\title{
Are you with me? \\ A Metadiscursive Analysis of Interactive Strategies in College Students' Course Presentations
}

\author{
MAGNUCZNÉ GODÓ ÁGNES* \\ Miskolc University, Hungary
}

Received: 24 February 2011 / Accepted: 29 May 2011

\begin{abstract}
In recent years increasing research attention has been devoted to the definition and development of presentation skills. As an interactive oral discourse type, the presentation is characterised by specific speech acts, of which cooperative acts have proved to be of a highly developmental nature (Sazdovska, 2009). The aim of the present paper is to report on a study which investigated the metadiscursive realisations of interactional acts in English major novice presenters' speeches as well as their correlation with raters' holistic perceptions of presentation quality.
\end{abstract}

\section{KEYWORDS}

Metadiscourse, engagements markers, interactional elements, dialogic elements, monologic elements

\section{RESUMEN}

En los últimos años se ha acentuado la investigación sobre el arte de la presentación oral. Según Sazdovska (2009), cada tipo de presentación tiene su discurso característico, pero todas las presentaciones comparten rasgos interactivos que se manifiestan de manera más o menos intensiva. Puede ser una destreza que se desarrolla con la práctica. El objetivo de mi estudio es presentar los resultados de una investigación en la que se analizan, por un lado, las manifestaciones metalingüísticas de las interacciones en las presentaciones de los estudiantes de Filología Inglesa, y, por otro, la percepción holística de los evaluadores sobre la calidad de tales presentaciones.

\section{PALABRAS CLAVE}

Metadiscurso, marcadores de compromiso, elementos interactivos, elementos dialógicos, elementos monológicos.

\footnotetext{
*Address for correspondence: Magnuczné Godó Ágnes. Department of English Language and Literature. Miskolc University. 3515 Miskolc-Egyetemváros. Hungary. Tel.: +36 46/565 215. E-mail: agnesgodo@gmail.com
} 


\section{INTRODUCTION}

"A speech should not just be a sharing of information, but a sharing of yourself" (http://thinkexist.com/quotes/ralph archbold, retrieved on $30^{\text {th }}$ May, 2011). The famous orator Ralph Archbold taps at the heart of presentations with this statement because anecdotal evidence meets research results to highlight the importance of interaction in speeches. Its importance having been increasingly recognised, interaction in academic and professional presentations has attracted significant research attention recently. On the basis of an interview study, Sazdovska (2009: 250) points out that it is highly developmental in nature: while novice presenters tend to focus on structuring, writing out content and practicing talk, expert presenters devote more effort to mapping out the audience's background and gaining their support and sympathy. There is intensive research on business presentations (e.g., Bereczky \& Sazdovska, 2005; McGee, 1999; Sazdovska, 2009; Yates \& Orlikowski, 2007), in which the aims, contents, structures and strategies tend to be more uniform, whereas the academic presentation appears to be a more fluid and versatile genre attracting fewer principled studies (e.g., Ädel, 2010; Luukka, 1994; Mauranen, 2001; Thompson, 2003). Despite their widespread application, academic student presentations are even more under-researched.

The present study is intended to join the line of research on the developmental nature of interaction in academic speeches. The author's experience as a university-level presentation skills instructor also confirms Sazdovska's (2009) conclusion that novice presenters view the presentation as a monologue in which they have to transmit information through a unidirectional channel. Taking them from this egocentric standpoint towards a more decentric orientation which enables them to perceive and serve the audience's needs and expectations is one of the most challenging instructional tasks. The investigation is rooted in the experience of an ESL presentation skills course which is part of the BA-level English Language and Literature programme at Miskolc University and is run in the fifth and sixth semesters. The study aims to explore what kind of interactive strategies contribute to a better overall perception of presentations, and what problematic strategies are applied by presenters whose presentations are judged to be less effective.

"Interactive strategies" have indeed attracted varied interpretations and cover a wide range of functions to be delimited here, following the interactive metadiscursive paradigm, to Hyland's (2010) engagement markers and Mauranen's (2001) dialogical and interactive elements. Engagement markers are metadiscursive elements which "explicitly address the readers, functioning to either selectively focus their attention, emphasise a relationship or include them as participants in the text situation" (Hyland, 1999: 104). Dialogic elements refer and respond to the audience's contribution, while interactive elements invite contribution from the audience or designate the next speaker (Mauranen, 2001).

The next section provides an overview of metadiscursive approaches to investigating interaction relevant for the present study. It will be followed by the methodological 
framework of the investigation in section 3, which introduces the research questions, defines the academic student presentation, the subject of the study, as a genre, describes the variables to be investigated, the participants and the data, and outlines the research procedures. The results of the study and the discussion of effective and problematic interactive strategies of ESL student presenters are presented in section 4.

\section{METADISCURSIVE APPROACHES TO THE STUDY OF INTERACTION IN ACADEMIC LECTURES AND PRESENTATIONS}

Interaction in academic lectures and presentations has attracted several approaches from metadiscourse analysis. As Ädel (2010:69) points out, there are two main strands: the broad or interactive model and the narrow or reflexive model. In the interactive model (e.g. Hyland, 1999, 2010; Luukka, 1994; Mauranen, 2001), metadiscourse is interpreted "as an umbrella term for the range of devices writers use to explicitly organize their texts, engage readers, and signal their attitudes to both their material and their audience" (Hyland, 2010:127). Here the researcher is not only concerned with the explicit, specific references to the actual participants of the current discourse, as is the case in the reflexive paradigm, but, for instance, also involves generic references to an assumed broader community which shares experience or opinion, or to other discourses which the participants of the actual situation may be familiar with. Mauranen (2001) distinguishes three metadiscursive element types in her study of university lectures: monologic elements organise the presenter's actual speech (Let's turn our attention now to...; In the following I wish to focus on ....), dialogic elements comment on the audience's contribution (It's easy; Yes, that's right), while interactive elements invite contribution from the audience or designate the next speaker (Which picture makes a more intensive impact on you?; Anna?). While Mauranen (2001) emphasises that spoken and written academic discourse should be studied using different frameworks, Ädel (2010) and Hyland (2010) claim that metadiscursive markers work similarly in speech and writing, and using the same analytical paradigm might provide potential points of comparison.

Hyland (1999) points out that not even academic writing is purely objective and factual: writers can only be convincing if they apply social and linguistic conventions that the intended audiences find persuasive. Meaning is constructed through social interaction, which evolves from "authorial stance" (p. 99): the ways in which writers/speakers represent themselves and attempt to involve their audience in shared thinking. These strategies involve "interactive" and "interactional markers" (Hyland, 2010). Interactive markers "help to guide the reader through text" (p. 128) by indicating transitions between main clauses (in addition, and, but), marking frame boundaries (finally, to conclude), referring to information from other parts of the text (as noted above), introducing evidentials from other texts (according to ...), and clarifying ideational content (namely, in other words). "Interactional markers", on the 
other hand, "concern the writer's efforts to control the level of personality in a text and establish a suitable relationship to his or her data, arguments and audience, marking the degree of intimacy, the expression of attitude, the communication of commitments, and the extent of reader involvement" (p. 128) and are expressed by hedges, boosters, attitude markers, engagement markers and self-mentions. Hedges such as possible, might, perhaps, believe mitigate the force of statements, while boosters (e.g., obvious, definite, of course) increase the force of propositions. Attitude markers including agree, prefer, should, need, unfortunately, remarkable express the author's affective attitude to the information conveyed, and engagement markers are metadiscursive elements which explicitly involve the readers in the text situation (Hyland, 1999). Without claiming to be exhaustive, Hyland lists the use of "we" and "you", questions, imperatives and digressions which directly address the audience as the main indicators of engagement. Finally, self-mentions are explicit ( $I$, the authors) or implicit (we, the study claims) references to the author.

In contrast with Hyland's (1999; 2010) and Mauranen's (2001) interactive models, the reflexive model adopts a narrower view with an emphasis on the capacity of language to refer to itself, that is, how speakers talk about the language they use, the communicative situation they are involved in or their own roles in it. Ädel (2010) represents the "lumping" approach in metadiscourse studies claiming that the same analytical framework can be used to explore oral and written discourse. However, she very clearly sets the boundaries of her approach by proposing four criteria: "explicitness", "world of discourse", "current discourse", and "speaker-writer qua speaker-writer, audience qua audience" (2010:75). "Explicitness" means that only explicit, intentional remarks on the evolving discourse comprise research interest; the "world of discourse" criterion suggests that metadiscursive actions of interest should be related to the world of the actual discourse and not to the "real world". The "current discourse" principle, on the other hand, requires that the elements should refer to the actual text not some other texts, and the same is true for the "speaker-writer qua speaker-writer, audience qua audience" principle: only references to the actual speaker/writer/audience functioning as discourse participants are included in the investigation. Overall, the distinction between specific and generic reference is a key guideline in the reflexive paradigm as it is only concerned with the former.

The present study follows the broader or interactive paradigm as it aims to explore student presenters' reference to and interaction with the actual audience as well as reference to a wider community that both the presenter and the audience are believed to be part of. The frequency and quality of direct interaction with the audience, and the application of generic and specific engagement markers are assumed to be variables distinguishing effective and less effective presentations, and the broader model provides a more flexible framework to integrate all these considerations. 


\section{METHODS}

\subsection{Aims and research questions}

As part of a reflective pedagogical practice, the present, largely qualitative, exploratory study aims to examine the developing interactive strategies of English-major college students in ESL academic student presentations with the methods of metadiscourse analysis, and raise issues for further research as well as classroom instruction. Based on the initial hypotheses introduced in the introduction, the following research questions are proposed:

1) What is the proportion of engagement markers (Hyland, 2010) in effective and less effective academic student presentations?

2) What proportion of engagement markers appears in monologic, dialogic and interactive elements (Mauranen, 2001)?

3) What is the proportion of generic and specific audience references within engagement markers (Hyland, 2010)?

4) To what extent do speakers apply other engagement markers such as imperatives, real and rhetorical questions (Hyland (2010)?

5) What kind of interactive elements (Mauranen, 2001) occur in the speakers' interaction initiations, and in what proportion?

6) What kind of dialogic elements (Mauranen, 2001) occur in the speakers' responses to the audience's contributions, and in what proportion?

7) How do these variables influence raters' holistic perceptions of presentation quality?

\subsection{Academic student presentation as a genre}

Before embarking on an analysis of interactive strategies in academic student presentations, it should be examined if it can be defined as a separate genre. Just as academic writing, academic presentation is also a socially constructed process and product (Hyland, 1999), thus the expected structure, level of formality and purpose of talks may widely differ across professions and disciplinary areas. Swales (1990) also points out that any genre type is defined by the set of context-dependent communicative purpose(s) realised by characteristic communicative events, which in turn determine(s) the structure of the discourse and influence(s) the choice of content and style. Based on Swales's genre concept, Sazdovska (2009) adopts a specific perspective and includes setting, status, affiliation and relationship between participants, communicative purposes and communicative events in her definition of the business presentation. She emphasises that presentations might have explicit, clearly defined communicative purposes and hidden, implicit ones as well. She also concludes that business presentations are characterised by four typical communicative acts:

1. organisational acts, orienting the audience in the discourse and managing activities (e.g., referring back, indicating, taking the floor, etc.); 
2. informative acts, conveying factual, descriptive or explanatory information (e.g., stating opinion, quoting, exemplifying, etc.);

3. territorial acts, containing the speaker's judgement of and attitude to the information and the situation, defending the speaker's borders and integrity, and also functioning as face-saving and face-threatening acts (e.g., contradicting, pushing for response, hedging, mitigating, etc.); and finally,

4. cooperative acts, creating a bond between the speaker and the audience (e.g., agreeing, proposing a solution, confirming, etc.) (2009: 78-82).

While communicative purposes and characteristic acts may be more straightforward in business presentations, defining the academic student presentation in the same vein presents a bigger challenge. First of all, while Sazdovska (2009) defines the business presentation as a genre that her students were probably aiming to practice in their future careers, such a link between the academic student presentation as a form of apprenticeship and a future careerrelated presentation genre is difficult to establish. If we consider, for instance, the pedagogical or academic career alternatives of arts students, it is evident that school teachers and academic lecturers need different competences regarding organising and presenting content, negotiating meaning, organising interaction or saving face, etc., which will further differ widely according to the various disciplinary areas. In addition, student presentations rarely have the genuine informative purpose and interested audience characteristic of real-life presentations as they are performed in classroom situations primarily to complete a course.

With several variables at hand, a more realistic alternative is to regard the academic student presentation as an educational genre in its own right. As a widespread pedagogical practice, it is an opportunity for students

1) to provide useful, personal contribution to the learning content, and

2) to acquire transferable presentation skills.

In view of the previous considerations, the following definition is proposed for the purposes of the present study:

An academic student presentation is a PLANNED and STRUCTURED TALK given SEMI-FORMALLY by an individual before fellow-students and instructors, who constitute an AUDIENCE. As the members of the audience are in different hierarchical relationships with the presenter, the academic student presentation is characterised with the multiple (and/or alternative) communicative AIMS of 1. demonstrating knowledge of a particular subject area, 2. reflecting various academic skills including analysis, argumentation, working with sources, etc., 3. showing awareness of acquired presentation skills, 4. providing interesting and informative content and format to engage and benefit fellow students.

The content and style requirements as well as the aims of the presentations that are analysed in the present study are described in the following section. 


\subsection{Participants and data}

The participants of the study include a full class of $3^{\text {rd }}$ year English major BA students at Miskolc University who attended the author's presentation skills seminar. All 10 students were ESL speakers; eight of them, having passed the comprehensive language exam at the end of the $1^{\text {st }}$ year, were advanced speakers, and the two students who had not passed the exam yet were at an upper-intermediate level. All participants were completing their first degree and had had some experience with class presentations in their previous first and second language learning environments, but no experience in real presenting situations and systematic instruction on presentation techniques before the course. On these grounds, they are considered to be novice presenters. In the first half of the course the students received training in

- preparation, timing, handling stage fright,

- focusing, matching content and structure to aims,

- fine-tuning presentations to context and audience,

- structuring, sign-posting,

- rhetorical devices,

- interactive strategies,

- body language,

- visuals.

Training included information input in a lecture course that accompanied the seminar, reading, discussion, language work, situational exercises, analysis of recorded presentations, and records of ongoing work. The second half of the seminar (weeks 9-14) was devoted to the presentations, which were discussed and analysed in class. The presentations were also recorded and the recordings were given to the students for further reflection.

The presentations were performed in English as a second language and were based on a semi-controlled topic: the students could choose any topic of their liking but it had to be connected to their specialisation in linguistics, British or American literature, history or civilisation. If someone had no idea, the instructors provided a list of topics from which the students could choose, and which they could further adapt to their personal interests. The aim of the presentation was to provide relevant and engaging content to their fellow students connected to a shared subject area as well as to demonstrate awareness of the skills that had been targeted by the presentation skills course. To be able to comply with these aims, the students had to take into account the shared academic and personal background as well as the compulsory nature of the audience's attendance: it was required to include a personal, analytical angle to the topic, to communicate something potentially new to the others and to add some interest element. The expected style was defined as semi-formal, so the presentation had to include some type of interaction of the students' choice regarding format and intensity, and it had to be presented in the form of free speech. Power Point visualisation was 
compulsory and the time limit was 15 minutes. The 10 recorded presentations comprising the data for the study are altogether 131 minutes 6 seconds and range between 7.06 and 23.30 minutes.

\subsection{The analytical framework}

Following the principles of the broader, interactive model of metadiscourse analysis represented by Hyland (1999, 2010) and Mauranen (2001), the study approaches interaction in academic student presentations from two angles. First, it maps out the use of engagement markers on the basis of Hyland (2010) examining

1) audience references:

- specific audience references to the actual audience present, including the use of the pronouns "you" and "we" as well as references to specific discourse participants by name, eg.:

If you take a look at these pictures, in 52 years everything has completely changed.

We may now turn our attention to two significant episodes in the novel because they are important for our investigation.

And then some cults that Lilla mentioned last week ...

- generic audience references to a wider community that both the presenter and the audience are part of, and which is assumed to share background knowledge and viewpoints, including the use of the pronouns "you" and "we", eg.:

What do we celebrate at this time?

If you are playing the game, and you are walking in the street and you go into a shop, it's a different scene, every time there is a new scene.

2) three other types of engagement markers: imperatives, real and rhetorical questions, eg.:

Now let's begin with the history. (imperative)

Now you can see two drawings of the Fisher King. What do you think, which

of the two is more interesting? (real question intended to attract a response)

And then we have a question: how did it happen that they have become part

of the American media and film industry? I've collected some alternatives.

(rhetorical question answered by the speaker)

Secondly, the analysis focuses on the interactive functions of the presentations realised by speech acts containing Mauranen's (2001) monologic, dialogic and interactive elements. To connect the analysis of Mauranen's elements to Hyland's engagement markers, it has been established what proportion of the above described engagement markers appears in the interactive speech acts containing Mauranen's elements. On the basis of the author's instructional experience, the integration of engagement markers in the whole discourse is 
hypothesised to be an indicator of internalised content, i.e., the source materials have been filtered through the presenter's own experience and judgement, while limiting the use of engagement markers to dialogic and interactive elements (especially to question-answer blocks) is assumed to signal that the speaker has problems with reproducing or identifying with the content.

To further explore the speakers' interactive strategies in direct speaker-audience exchanges, the last aspect of the analysis is extended to all speech acts including

1) interactive elements (Mauranen, 2001) functioning as speakers' initiations

- real questions, eg.:

It was a bit longer, excuse me, but what do you think, which country does it belong to?

- calls for contribution, eg.:

Judit?

- encouragement, e.g.:

If you can say ....?

It's easy ...

2) dialogic elements (Mauranen, 2001) functioning as speakers' responses to audience contributions

- acknowledgement or short qualification of answer, eg.:

Yes. It's true.

- repetition, summary or paraphrase of answer, e.g.:

What about touching?

//Maybe women touch more ...?//

Yes, women touch more. $O k$.

- extension of answer with related comment, eg.:

First of all I'd like to ask you if you have seen a film about native Americans.

Have you?

//Yes ... //

Yes. And what was in these films?

//The Indians lived close to nature and they were brave and honest ...//

Well, thank you, this is one of the portrayals that you could see. On the other

hand, there are many other images that you can see in these films.

\subsection{Procedures}

As one aim of the study is to relate specific interactive strategies to presentation quality, the presentations were evaluated on a 1-5 scale and rank ordered from 1 to 10 by three raters. The 
author acted as one of the raters and thus included the students' presentation grades as one set of data. The other two raters were also asked to read the course presentation requirements (see Appendix 1) and perform holistic evaluation of the recorded presentations judging how effectively the presenters completed the task and what effect the presentation made on them. The grades and the rank order numbers of the 3 raters were averaged and the final ranking was established on this basis. The evaluations and the rank order can be seen in Appendix 2.

The presentations were then transcribed and sectioned applying the speech act as the unit of analysis defined by Searle (1969:16) as "the basic or minimal unit of linguistic communication". It appeared as the most suitable unit of analysis as many of the categories investigated are functional categories such as "acknowledgement" or "encouragement". Being a functional unit expressing a single proposition, the speech act also provides a flexible category to accommodate a single word such as "yes" replaceable by the proposition "this is the right answer", but also a complex sentence.

The analysis of the transcripts involved identifying engagement markers (Hyland, 1999; 2010) and establishing the proportion of specific and generic audience references as well as the frequency of imperatives, real and rhetorical questions. It was then observed what proportion of these engagement markers appears in speech acts containing Mauranen's (2001) monologic, dialogic and interactive elements. A further analysis of interactional acts involved the identification of all speech acts containing Mauranen's (2001) dialogic and interactive elements, and the exploration of initiation and response strategies (cf. section 3.4). Patterns of interaction were analysed with a view to interactive - dialogic element ratios as well as subcategories. In the final phase of the analysis, all identified variables were related to the holistic assessment of presentations, and emerging patterns of effective and problematic interaction were identified.

\section{RESULTS AND DISCUSSION}

\subsection{Engagement markers}

As table 1 shows, both audience references and other engagement markers demonstrate the same tendency. The least effective presentations are characterised by the lowest marker frequencies, and in the case of the other engagement markers (EM), this tendency extends to the presentations marked 3. Between the presentations marked 4 and 5, there does not seem to be a consistent difference. 


\begin{tabular}{|c|c|c|c|}
\hline Presenter & Grade & 1 AR/ X secs. & 1 EM/ X secs. \\
\hline \hline Tekla & 5 & 20 & 48.3 \\
\hline Iván & 5 & 26.6 & $100.7^{*}$ \\
\hline Éva & 4 & 39.2 & $18.3^{*}$ \\
\hline \hline Vivien & 4 & $12.9^{*}$ & $25^{*}$ \\
\hline Csilla & 4 & 22.5 & $75^{*}$ \\
\hline Gabriella & 4 & $21.4^{*}$ & 50.6 \\
\hline \hline Teodóra & 3 & 35.7 & 482 \\
\hline \hline Emma & 3 & $12.1^{*}$ & 238.5 \\
\hline Vilma & 2 & 69.3 & 161.7 \\
\hline \hline Endre & 2 & 75 & - \\
\hline \hline
\end{tabular}

Table 1: Frequency of audience references (AR) and other engagement markers (EM) per seconds (secs.)

Among the best ones, Ivan's rather low, 1 EM/ 100.7 secs. frequency deserves attention. This suggests low interactivity, though the functional analysis of interactive and dialogic elements will show that his interaction was very effective. In the last four presentations the low frequency of other engagement markers clearly signals the lack or insufficiency of direct interaction with the audience, but even in the case of Csilla's relatively good presentation with a $1 \mathrm{EM} / 75$ secs. frequency, all three raters alternatively noted that "it was boring", "lacked the necessary enthusiasm" or "limited communication to the intro of the topic". Éva and Viven, on the other hand, are distinguished by very high frequencies of other engagement markers (1 EM/18.3 secs. and 25 secs. respectively), and Vivien also by the second highest audience reference figure (1 AR/12.9 secs.). Despite the problems they had with the content of their talks (to be discussed later) and the fact that Vivien's presentation was the shortest one ( 7 mins. 5 secs.), both of them attracted positive comments from the raters relating to their enthusiasm and involvement. While Emma demonstrated an even higher frequency of audience reference (1 AR/12.1 secs.) than Vivien, it was combined with a very low other engagement marker frequency (1 EM/238.5 sec.): direct interaction here was compensated for by a heavy reliance on shared experiences and assumed agreement, which created the feeling of superficiality and overgeneralisation, thus making a negative impression on the raters. As reflected by Emma's and Gabriella's presentation, the overall frequency of engagement markers is not, in itself, a reliable indicator of interaction quality. Thus, audience references are further analysed in terms of generic and specific references, and in terms of their occurrence in monologic, dialogic and interactive elements (Mauranen, 2001). 
The general tendency evolving from the audience reference distribution figures in table 2 is that specific references dominate over generic references. In this aspect, no significant difference appears between the most and the least effective presentations, but the opposite tendency indicates problematic practices, as in Vivien's (GEN=56.2\%) and Emma's $(\mathrm{GEN}=86.1 \%)$ cases. The high proportion of generic audience references indicates intensive involvement with their topics. In Vivien's speech, the dominance of generic references was combined with a large proportion of audience markers in interactional acts $(\mathrm{IA}=72.5 \%)$ and a high frequency of other engagement markers (1 EM/ 25 seconds). This resulted in a highly interactive but not very content-rich speech in which most information input resulted from direct interactions with the audience and references to assumed shared knowledge, experience or agreement.

\begin{tabular}{|c|c|c||c|c|}
\hline Presenter & 1 AR/ X secs. & SPEC \% & GEN\% & IA \% \\
\hline Tekla & 20 & 58.6 & 41.4 & 48.3 \\
\hline Iván & 26.6 & 84.9 & 15.1 & 71.7 \\
\hline Éva & 39.2 & $100^{*}$ & - & $100^{*}$ \\
\hline Vivien & 12.9 & 43.8 & $56.2^{*}$ & $72.5^{*}$ \\
\hline Csilla & 22.5 & 60 & 40 & 50 \\
\hline Gabriella & 21.4 & $100^{*}$ & - & 51.9 \\
\hline Teodóra & 35.7 & 62.9 & 37.1 & $29.1^{*}$ \\
\hline Emma & 12.1 & 13.9 & $86.1 *$ & 57.1 \\
\hline Vilma & 69.3 & 57.1 & 42.9 & 70 \\
\hline Endre & 75 & 70 & 30 & \\
\hline
\end{tabular}

Table 2: Overall frequency of audience references per seconds, distribution of specific (SPEC) and generic (GEN) audience references, and the proportion of audience references in interactive acts (IA)

Emma, on the other hand, could not create effective interaction with the audience: the dominance of generic references, and the low representation of audience markers in interactional acts $(\mathrm{IA}=29.1 \%)$ indicate that instead of mapping out the opinions and experiences of the actual audience, she communicated a large portion of information as assumed shared background or generally held views. However, the overgeneralised content was partially rooted in linguistic shortcomings in this case: although the presenter was confident in and enthusiastic about the content and she made an appreciable effort to present her speech freely, she lacked the appropriate ESL resources and practice to formulate the main ideas precisely on the spot - instead, she implied or sometimes lengthily interpreted 
them through repeated references to an assumed collective background. While this contributed to the impression that her presentation was "rambling" and "uninformative" according to the raters, it also raises the question when it is justifiable to rely on an assumed shared background. This strategy was definitely problematic in this case when the presenter talked about the unacceptable social practice of internet game addiction as illustrated by the following example:

Example 1. Inappropriate reliance on shared background

We are the main reason why we became addicted. We can blame the games but actually nobody forces us to play. So everything depends on our views and how we decide things.

While speaking, the presenter also recognised that the audience could not be expected to fully identify with the antisocial or dangerous behaviour or to have shared experience in this area, so she made interesting attempts at two points of the presentation to distance the negative practices, one of which can be seen in the next example:

Example 2. Changing viewpoints

I think everybody feels sometimes I want to kill somebody, I'm so nervous please leave me alone. We have to express our anger somehow and these games can help us to vent our anger and feelings.

The unacceptable idea of feeling the urge to kill is distanced by attributing it to "everybody" not explicitly including the audience present, then it is dramatised by using the first person singular. When returning to the acceptable practice of venting anger, the speaker returns to the generic inclusive first person plural. Such viewpoint shifts represent positive strategies and novice speakers' awareness should be raised to when and how - through distancing and narrowing - it is justifiable to rely on shared community experience.

While Emma overused generic audience references, Éva and Gabriella represented the other extreme: all their audience markers were references to the specific audience, and in Éva's case all, in Gabriella's case $87.9 \%$ of the audience markers functioned in interactional acts. The lack of generic references in both cases indicates a lack of confidence regarding the 
content: the speakers did not internalise the material and relied intensively on their formal texts, which they read from their manuscripts or slides. To compensate for this shortcoming, they integrated several question-answer blocks into their speeches, which, however, were sharply divided from the rest of the discourse with their informal style and interactive character, as is evident in the following example:

Example 3. Unintegrated interaction

Let's do the multilingualism quiz. So my first question would be the following: (turns to slide and reads it out) children who learn more than one language do not become fluent in any of these languages. (turns back) What do you think about it, is it true or false? ... False? ... True?

//False//

$O k$, so let's see the answer for it. (turns to slide as if to check) Yes, it is false. (reads out extension) Children can become fluent in more than one language ...

In this extract the speaker underlines the division between the interactive parts and the informative parts with body language as well, turning towards the audience when performing interaction and turning away when providing informative content.

Table 3 presents the frequency of the three other engagement markers: imperatives, rhetorical and real questions. All presenters except for the last one recognised their importance and integrated them into their speeches, but the more effective presentations graded 4 and 5 clearly utilized these engagement markers more frequently. Imperatives were dominantly used for signposting (monologic function) and encouragement (interactive function) and showed the consistent tendency that the more effective the presentation was, the more frequently this element occurred. The exception is Gabriella with a rather high frequency figure (1 IMP/141.6 secs.), which resulted from the fact that she (over)used imperatives introducing all new text components in this way. There were altogether 14 examples of "Let's ..." imperatives in her speech making this strategy rather monotonous. As example 3 above shows, even within one initiation-response event the "let's ..." imperative was used twice to introduce the activity and to provide the right answer. 


\begin{tabular}{|c|c|c|c|}
\hline Presenter & 1 IMP/X secs. & 1 RHET/X secs. & 1 REAL/X secs. \\
\hline Tekla & - & 64.4 & 290 \\
\hline \hline Iván & 201.4 & - & 705 \\
\hline Éva & 206 & 206 & $27.5^{*}$ \\
\hline \hline Vivien & 425 & & 68.7 \\
\hline Csilla & 450 & 128.6 & 300 \\
\hline \hline Gabriella & $141.6^{*}$ & 354 & 177 \\
\hline \hline Teodóra & - & - & 482 \\
\hline Emma & 477 & 477 & 485 \\
\hline \hline Vilma & - & 229 & - \\
\hline Endre & - & - & \\
\hline
\end{tabular}

Table 3: Frequency of other engagement markers: imperatives (IMP), rhetorical (RHET) and real (REAL) questions per seconds

Rhetorical questions were utilized the least frequently and they were the most problematic. In this corpus all presenters used this device as monologic elements for signposting and introducing new content. Tekla's unusually high frequency of rhetorical questions (1 RHET/ 64.4 secs.) reveals a positive strategy of introducing the main topics of the speech by raising rhetorical questions as can be seen in example 4 :

Example 4. Rhetorical questions introducing main points

First I'd like to ask you what let them, the native Americans, to appear in the media? Was it because US interest grew? Was it because there was less discrimination for native Americans? Or was it because of the telecommunication acts?

The number of rhetorical questions is increased by quasi-items resulting from transforming real questions into rhetorical questions as the presenters found real questions too timeconsuming or lost confidence on the way, as it is illustrated in the following example:. 
Example 5. Changing real question into rhetorical question

What do you know about Xmas? (looks up, very short pause)... What are the symbols of Xmas? What do we celebrate at this time? (does not look up, very short pause)... We know that Christmas is one of the most ancient celebrations ...

Vilma evidently planned these to be real questions to initiate a warm-up discussion at the beginning. However, she lost courage and though she looked up and hesitated for half a second, she hurried on to add two further questions. After these questions she did not look at the audience any more, indicating that no contribution was expected.

Real questions appear to be the most frequent of the three elements in table 3 . Interestingly enough, though, the highest frequency items do not belong to the most effective presentations and signal problems. Éva (1 REAL/27.5 secs.) misinterpreted the role of questions and started every topic block with a real interactive question with rising intonation and a pause. This means that these questions had both monologic and interactive functions. Such overloaded questions, however, proved dysfunctional, and the presenter realised that 1) many of these topic-introducing questions were too vague or general for the audience to answer, so she "doubled" these questions and added further qualifying questions; 2) the questioning method was time consuming, so keeping the interactive question character, she shortened the pauses and hurried on to provide her own answer. A combination of the two strategies is illustrated by the following quote:

Example 6. Vague question and "doubling",

What do you think about men's and women's language? ... What about adjectives and adverbs? ...(answers herself).... Yes .... What about intensifiers? .... (answers herself)

Iván's unusually low real question frequency (1 REAl/ 705 secs.) might indicate a problem of interaction in one of the best presentations. However, a more careful analysis of interactive elements to follow in the next section proves that the presenter could actually realise effective communication by using a variety of interactive devices. 


\subsection{Dialogic and interactive elements in initiations and responses}

This facet of the analysis explores the patterns of initiations and responses: what efforts the presenters make to encourage the audience to contribute, and how they try to respond to such contributions and integrate their content into their speeches to create meaning together. As table 4 shows, two clear tendencies evolve:

\begin{tabular}{|c||c|c|c|c|c|}
\hline Presenter & IE \% & DE \% & 1 IE/X secs. & 1 DE/X secs. & Total n \\
\hline \hline Tekla & 42 & 58 & 193.3 & 145 & 7 \\
\hline Iván & 25 & 75 & 201.4 & 67.1 & 28 \\
\hline Éva & 59.7 & 40.3 & $22.3^{*}$ & 33 & 21 \\
\hline Vivien & 74 & 26 & $32.7^{*}$ & 53.1 & 6 \\
\hline \hline Csilla & 50 & 50 & $300^{*}$ & $300^{*}$ & 18 \\
\hline Gabriella & $38.9 *$ & $61.1^{*}$ & 101.1 & 64.4 & 4 \\
\hline Teodóra & 50 & 50 & 428 & 428 & - \\
\hline \hline Emma & - & - & - & - & - \\
\hline \hline Vilma & 100 & - & 485 & - & - \\
\hline Endre & - & - & - & & \\
\hline
\end{tabular}

Table 4: Proportion and frequency of interactive elements (IE) and dialogic elements (DE)

Firstly, the less effective presentations marked 2 and 3 contain no or minimal interaction. Here it is interesting to observe Csilla's performance, whose otherwise good talk was regarded as limited in interaction by the raters. The tendency previously indicated by the low engagement marker frequency figure is also reinforced by the low interaction frequency figures (1 IE/300 secs. and $1 \mathrm{DE} / 300$ secs.), which means that she did not include further interactive elements to compensate for the low number of directives and questions. The explanation for Iván's effective communication can also partly be found here: while his real question frequency was very low (1 REAL/705 secs.), his interactive element frequency is significantly higher (1 IE/201.4 secs.), which indicates the combination of different initiating devices.

The best presentations do not stand out with very high frequency results, and indeed such high numbers indicate problematic practices in the case of Éva (1 IE/22.3 secs.) discussed in the previous section and Vivien (1 IE/32.7 secs.). While in Éva's presentation the similar real question (1REAL/27.5 secs.) and interactive element (1 IE/22.3 secs.) frequencies indicate that she added further questions to clarify the dysfunctional topic- introducing questions, Vivien was slightly impatient and could not tolerate pauses. Afraid that the 
audience would not respond, she added further helping questions (1 REAL/68.7 secs.) and encouragements (raising her overall interactive element frequency to $1 \mathrm{IE} / 32.7$ secs.) often to answer herself at the end, as can be seen in the following excerpt:

Example 7. Filling the pause after the main question

Do you think that if you compare it to the European .... to what the Europeans think about these animals, which of these mean good symbols also for the Europeans? ... If you can say ...? ... I think it's easy ... For example ... horse? ... It could mean power if you think about cars although it also means loyalty as we all know.

The second noticeable tendency is that in the best presentations the number of dialogic elements dominates over the number of interactive elements. This not only means that every audience answer initiated by a presenter question was responded to, but also that effective presenters, for instance, Ivan used response chains to react to and integrate audience contribution:

Example 8. Response chain

I would like you to ... when I launch a track, I would like you to say which country I am talking about. [...] So listen, first one ... (music) It was a bit longer, excuse me, but what do you think, which country does it belong to? ... Judit? ...

//Is it ... some kind of Arab?//

No ... (rising intonation, looks around for further answers)

//South America.//

Yes! Bingo! Latin America. They are called Metal Heads and they are from New Jersey but their origins are from Latin America.

In the highlighted response chain, the speaker first acknowledged and qualified the answer, then repeated the key information to fix it in the audience's mind and used it as a starting point to provide a related extension. 
Éva's and Vivien's distribution figures, showing a dominance of interactive elements over dialogic ones, further illustrate the tendency that a significant number of their numerous questions were dysfunctional and did not attract an answer to which the presenter could react, or the presenter missed the opportunity to react to audience contributions completely. Gabriella's distribution figures, on the other hand, seem to follow the strategy of the best presentations, but a more detailed analysis reveals the reason why her interactions were not effective.

As table 5 shows, the effective presentations marked 4 or 5 demonstrate a greater variety and larger number of interactive and dialogic elements. While Gabriella's figures conform to this trend, her unrelated responses are problematic: she wanted to provide information as part of her interaction with the audience, but because she was insecure about the content, she could not relate these information blocks to the audience's answers. This is a further detail to confirm the conclusion that her uncertainty of the content undermined her presentation and this could not be compensated for by integrating interactive blocks.

Regarding the proportion of real questions and calls or encouragements, table 5 suggests that effective presentations marked 4 and 5 utilised both strategies, with real questions dominating over calls and encouragements. Here Ivan's figures are remarkable with a larger proportion of calls and encouragements, which reflects his consistent, positive strategy to initiate multiple contributions to the same question.

Ideally, the audience's answers initiated by the presenter should be acknowledged, which was fulfilled in Tekla's and Iván's cases, who have an equal proportion of real questions and acknowledgements or a higher proportion of acknowledgements indicating several responses to the same question or multiple acknowledgements. Even in the case of the presentations marked 4 this seems to be a problematic issue, though. Éva and Vivien have a very low proportion of acknowledgements in comparison with the proportion of real questions (Éva: acknowledgement $=17.7 \%$, real questions $=48.4 \%$; Vivien: acknowledgement $=8.7 \%$, real question $=52.3 \%$ ), and also in Csilla's and Gabriella's case, there are only half as many acknowledgements as real questions. These figures again indicate either many unanswered questions or no reaction to several contributions.

Repeating or summarising the audience's answers is a positive strategy only followed systematically by Ivan (real question $=7.1 \%$, repetition $=10.7 \%$ ) and Gabriella (real question= $22.2 \%$, repetition $=16.7 \%$ ). Related extensions are also effective forms of message transfer as they provide information in reaction to the listeners' contribution, thus integrating new information in an interactive manner, creating knowledge together with the audience. In the case of the two best presentations and Gabriella's presentation, the proportion of real questions is equal to or smaller than the proportion of extensions, which means that on average, each audience answer initiated by a question was integrated into the flow of the speech by one or more related extensions. In Gabriella's case, however, $11.1 \%$ of the responses are unrelated, which breaks the flow of the interaction. 


\begin{tabular}{|c|c|c||c|c|c|c|c|}
\hline Presenter & Real ques.\% & $\begin{array}{c}\text { Call+ } \\
\text { Encour.\% }\end{array}$ & $\begin{array}{c}\text { Acknow. } \\
\text { answer\% }\end{array}$ & $\begin{array}{c}\text { Repeat } \\
\text { answer \% }\end{array}$ & $\begin{array}{c}\text { Related } \\
\text { extension\% }\end{array}$ & $\begin{array}{c}\text { Unrelated } \\
\text { extension\% }\end{array}$ & Total n \\
\hline Tekla & 29 & 13 & 29 & & 29 & & 16 \\
\hline Iván & 7.1 & $17.9 \%$ & 39.3 & 10.7 & 25 & - & 28 \\
\hline Éva & 48.4 & 11.3 & 17.7 & 12.9 & 9.7 & & 62 \\
\hline Vivien & $\mathbf{5 2 . 3}$ & 21.7 & $\mathbf{8 . 7}$ & 4.3 & 13 & & 23 \\
\hline Csilla & $\mathbf{5 0}$ & & 33.3 & & 16.7 & & 6 \\
\hline Gabriella & $\mathbf{2 2 . 2}$ & 16.7 & 11.1 & 16.7 & 22.2 & $11.1 *$ & 18 \\
\hline Teodóra & $\mathbf{5 0}$ & & 25 & & 25 & & 4 \\
\hline Emma & - & - & - & - & - & - & - \\
\hline Vilma & 100 & - & - & - & - & - & 1 \\
\hline Endre & - & - & - & - & - & - & - \\
\hline
\end{tabular}

Table 5: Distribution of interactive (real questions, calls and encouragement) and dialogic (acknowledgement of answer, repetition or summary of answer, related extension, unrelated extension) elements

\section{CONCLUSION}

The primary aim of the present study was to direct attention to academic student presentation as a wide-spread educational genre, and within that, to a key skill of a highly developmental nature: interaction. As the corpus is of a limited size, the highlighted phenomena and observations are issues for further investigation and awareness-raising rather than generalizable conclusions. With this in mind, however, it can be stated that the study revealed recognisable differences in interactive strategies between effective and less effective presentations.

Effective presenters applied a balanced use of references to the actual audience and a general community. "Balance" here refers, on the one hand, to a moderate and principled use of audience references in view of the topic discussed, and, on the other hand, to the dominance of actual audience markers over generic ones. The strategic use of generic and specific audience references for "distancing" and "involvement" are important issues here for awareness-raising. The functional analysis of generic references could be a further research perspective especially because in contrastive rhetorical studies of academic writing, generic 
reference has been found to be a culture-dependent feature applied more intensively by Central-European writers than by Anglo-Americans (e.g., Magnuczné Godó, 2008).

Effective presenters were also distinguished by a higher proportion of interactive and dialogic elements, with dialogic elements dominating. This might derive from attracting and responding to multiple audience contributions related to one question, and also from providing multiple response chains in reaction to audience answers. While acknowledging the answer is a minimal response requirement from the presenter, the repetition or summary of the audience's contributions and providing a related response seemed to be effective ways of integrating the answers into the flow of speech.

Less successful speeches clearly demonstrated a set of problematic interactional strategies, too. A low frequency of engagement markers indicates that the presenter was not involved with the topic or the material was not internalised. The excessive use of engagement markers, on the other hand, sometimes resulted in too intensive interaction and/or presenting most information as shared knowledge experience, both of which decreased the credibility of the speaker. If the material had not been learnt properly, presenters tended to find it difficult to integrate interactive blocks into the flow of speech: in such cases the interactive blocks were sharply divided from the highly structured and formal informative parts.

Except for the least impressive presentation, all presenters in the study perceived questions as effective ways of organising content and initiating contact with the audience. However, the question strategies were not always realised with appropriate confidence and planning. A lack of confidence or consideration was indicated by changing the illocutionary function of questions while actually presenting them. This may have resulted from the speaker's fear that the audience would not respond or the presenter would not be able to react to contributions, or alternatively, from the recognition that the question was not appropriate. Whatever the reason, the different messages conveyed by linguistic and paralinguistic devices were confusing for the audience, which the presenter should avoid by extending careful planning beyond informative content to include interactive strategies as well.

While a lack of questioning techniques is definitely a feature of less successful presentations, the excessive use of questions, in itself, did not guarantee effective interaction either. A large number of questions sometimes resulted from qualifying questions to accompany main questions judged by the speaker to be too general or vague, or filling the pauses after the main question with further encouraging or clarifying questions if there is no immediate response from the audience. Even if the questions were functional, real interaction could only be realised if the speaker responded to the answers of the audience, which was also a common problem point.

In conclusion, it can be stated that further research is needed to explore the genrespecific speech acts and metadiscursive strategies characterising the academic student presentation as a genre. Although it is a wide-spread educational practice, its features are defined (and understood) surprisingly loosely, thus the expected competencies often remain 
opaque for the learners. This might lead to the belief that the required skills are primarily personality dependent features that cannot be developed or create presentation situations from which neither the presenter nor the audience can properly benefit. The aim of this study was to highlight selected interactive strategies and analyse their effect on raters. Making such strategies conscious and recognisable raises awareness, fosters self-reflection and creates the confidence in students that interactive skills are learnable, which are the keys to development.

\section{ACKNOWLEDGEMENTS}

I would like to thank Dr. Harry Edward Bailey (Miskolc University) and Zsolt Magnucz (OUP Hungary) for their help and support.

\section{REFERENCES}

Archbold, R. http://thinkexist.com/quotes/ralph_archbold. Retrieved on 30 ${ }^{\text {th }}$ May, 2011.

Ädel, A. (2010). Just to give you kind of a map of where we are going: A taxonomy of metadiscourse in spoken and written academic English. Nordic Journal of English Studies 9(2): 69-97. http://ojs.ub.gu.se/ojs/index.php/njes/article/view/415/403. Retrieved on 15th April, 2011.

Bereczky, K. \& Sazdovska, J. (2005). Structure and strategies of the question and answer session of student presentations. Annals of the International Business School 2005, 64-73.

Hyland, K. (1999). Disciplinary discourses: Writer stance in research articles. In: C. N. Candlin \& K. Hyland (Eds.), Writing: Texts, processes and practices (pp. 99-121). London and New York: Longman.

Hyland, K. (2010). Mapping interactions in academic writing. Nordic Journal of English Studies, 9(2), 99-123. http://ojs.ub.gu.se/ojs/index.php/njes/article/view/415/403. Retrieved on 15th April, 2011.

Luukka, Minna-Riitta. (1994). Metadiscourse in academic texts. In: B. L. Gunnarsson, P. Linell \& B. Nordberg (Eds.), Text and talk in professional contexts. Selected papers from the international conference "Discourse and the professions," Uppsala, 26-29 August, 1992. (pp. 77-88). Uppsala: ASLA, The Swedish Association of Applied Linguistics.

Magnuczné Godó, Á. (2008). Cross-cultural aspects of academic writing: A study of Hungarian and North American college students' L1 writing. In IJES, 8(2), 65-112.

Mauranen, A. (2001). Reflexive academic talk: Observations from MICASE. In: R. Simpson \& J. Swales (Eds.), Corpus linguistics in North America: Selections from the 1999 Symposium. (165-178). Ann Arbor, MI: University of Michigan Press.

McGee, A. (1999, November). The sociolinguistic aspects of the business presentation and its importance for teaching. Intercultural Communication, issue 2. http://www.immi.se/intercultural/nr2/mcgee/htm. Retrieved on 15th April, 2011.

Sazdovska, J. (2009). The intentionality model of presentations. PhD dissertation. ELTE-SEAS, Budapest.

Searle, J. (1969). Speech acts: An essay in the philosophy of language. Cambridge, England: Cambridge University.

Swales, J. (1990). Genre analysis: English in academic and research settings. Cambridge: CUP.

Thompson, S. E. (2003). Text-structuring metadiscourse, intonation and the signalling of organisation in academic lectures. Journal of English for Academic Purposes, 2, 5-20.

Yates, J. \& Orlikowski, W. (2007). The Power Point presentation and its corollaries: How genres shape communicative action in organisations. In: M. Zachry \& C. Thralls (Eds.), The cultural turn: Communicative practices in workplaces and the professions. Amityville, NY: Baywood 
Publishing. http://seeit.mit.edu/Publications/ YatesOrlikowski-PP.pdf Retrieved on 6th January, 2011.

\section{APPENDIX 1. PRESENTATION REQUIREMENTS}

\section{Content and organisation}

The presentations should

1) be informative,

2) have a recognisable structure (intro, thematic components, conclusion),

3) contain aspects of analysis (comparison/contrast, evaluation, etc.),

4) be signposted,

5) contain interest elements (stories, surprising, facts, etc.).

\section{Language and style}

The presenter should

1) speak clearly and loud enough,

2) use the necessary thematic vocabulary confidently,

3) have appropriate and consistent style,

4) speak freely, without relying excessively on notes.

\section{Visuals}

The visuals should be

1) easy to see,

2) relevant,

3) well integrated into the speech,

4) represent the backbone of the speech.

\section{Body language}

The presenter should

1) keep eye contact,

2) use her/his hands to accompany the message,

3) have confident posture,

4) occupy the space.

\section{Interaction with the audience}

The presenter should

1) initiate conversation with the audience,

2) react to the audience's contributions,

3) use rhetorical questions and directives to direct the audience's attention. 


\section{APPENDIX 2. GRADES AND RANKING OF PRESENTATIONS}

\begin{tabular}{|l|l|l|l|l|}
\hline Presenters & Rater 1 & Rater 2 & Rater 3 & $\begin{array}{l}\text { Final average } \\
\text { grade }\end{array}$ \\
\hline Tekla & 5 & 5 & 4 & 5 \\
\hline Iván & 5 & 5 & 4 & 5 \\
\hline Éva & 4 & 4 & 5 & 4 \\
\hline Vivien & 3 & 4 & 4 & 4 \\
\hline Csilla & 5 & 4 & 4 & 4 \\
\hline Gabriella & 4 & 3 & 4 & 4 \\
\hline Teodóra & 3 & 3 & 4 & 3 \\
\hline Emma & 3 & 3 & 3 & 3 \\
\hline Vilma & 2 & 2 & 3 & 2 \\
\hline Endre & 2 & 2 & 2 & 2 \\
\hline
\end{tabular}

Table 1. Grades

\begin{tabular}{|l|l|l|l|l|}
\hline Presenters & Rater 1 & Rater 2 & Rater 3 & $\begin{array}{l}\text { Final average } \\
\text { rank }\end{array}$ \\
\hline Tekla & 2 & 1 & 2 & 1 \\
\hline Iván & 1 & 2 & 3 & 2 \\
\hline Éva & 4 & 3 & 1 & 3 \\
\hline Vivien & 5 & 5 & 5 & 4 \\
\hline Csilla & 3 & 4 & 4 & 5 \\
\hline Gabriella & 6 & 6 & 7 & 6 \\
\hline Teodóra & 7 & 7 & 6 & 7 \\
\hline Emma & 8 & 9 & 8 & 8 \\
\hline Vilma & 9 & 8 & 9 & 9 \\
\hline Endre & 10 & 10 & 10 & 10 \\
\hline
\end{tabular}

Table 2. Rank order 